IRA-International Journal of Applied Sciences ISSN 2455-4499; Vol.03, Issue 03 (2016)

\title{
On the Distribution of the Zeros of Lacunary type Polynomials
}

\author{
B. A. Zargar \\ Department of Mathematics \\ University of Kashmir, Srinagar, India.
}

DOI: http://dx.doi.org/10.21013/jas.v3.n3.p10

\section{How to cite this paper:}

Zargar, B. (2016). On the Distribution of the Zeros of Lacunary type Polynomials. IRAInternational Journal of Applied Sciences (ISSN 2455-4499), 3(3).

doi:http://dx.doi.org/10.21013/jas.v3.n3.p10

(C) Institute of Research Advances

\section{(cc) EY-NC}

This works is licensed under a Creative Commons Attribution-Non Commercial 4.0 International License subject to proper citation to the publication source of the work.

Disclaimer: The scholarly papers as reviewed and published by the Institute of Research Advances (IRA) are the views and opinions of their respective authors and are not the views or opinions of the IRA. The IRA disclaims of any harm or loss caused due to the published content to any party. 


\section{ABSTRACT}

In this paper we use matrix methods and Gereshgorian disk Theorem to present some interesting generalizations of some well-known results concerningthe distribution of the zeros of polynomial. Our results include as a special case some results due to A .Aziz and a result of Simon Reich-Lossar.

(AMS) Mathematics Subject Classification: 30c10, 30c15.

Key words and Phrases: Lacunary type polynomial, coefficient, zeros.

\section{Introduction and Statement of Results}

The following result due to Cauchy [4] is well known in the theory of the distribution of the zeros of a polynomial.

Theorem A. Let

$$
P(z)=z^{n}+a_{n-1} z^{n-1}+\ldots+a_{1} z+a_{0},
$$

be a polynomial of degree $n$ then all the zeros of $\mathrm{P}(\mathrm{z})$ lie in the disk

$|z|<1+A$

where $A=\max \left|a_{j}\right|, j=0,1,2, \ldots, n-1$.

About forty years ago, in connection with Cauchy's Classical result (Theorem A) Simon Reich proposed and among others Lossers[6] verified that if $a_{n-1}=0, Q>1$, then all the zeros of

$$
P(z)=z^{n}+a_{n-1} z^{n-1}+\ldots+a_{1} z+a_{0},
$$

lie in the circle

$|z| \leq Q+Q^{2}+\cdots+Q^{n-1}$

Aziz [2] generalized the problem to lacunary polynomials and showed that the assertion (2), remains valid even if we do not assume that $Q>1$. In fact he proved:

Theorem B. Let

$$
P(z)=a_{n} z^{n}+a_{r} z^{r}+\ldots+a_{1} z+a_{0},
$$

$a_{r} \neq 0,0<r \leq n-1$ be a polynomial of degree $\mathrm{n} \geq 2$, with real or complex coefficients if 


$$
Q=\left\{\underset{0 \leq j \leq r}{\operatorname{Max}}\left|\frac{a_{j}}{a_{n}}\right|\right\}^{1 / n}
$$

then all the zeros of $\mathrm{P}(\mathrm{z})$ lie in the disk

$$
|z| \leq Q+Q^{2}+\ldots+Q^{r+1}
$$

Where $0 \leq \mathrm{r} \leq \mathrm{n}-1$. Other results of similar type were obtained among others by Alzer [1], Bell[3], Guggenheimer[5]. Mohammad[7], Rahman[8], Walsh [10] (see also [9]).

As a generalization of Theorem $\mathrm{B}$, we prove:

Theorem 1. Let

$$
P(z)=a_{n} z^{n}+a_{r} z^{r}+\ldots+a_{1} z+a_{0},
$$

$a_{r} \neq 0 \quad 0 \leq r \leq n-1$ be a polynomial of degree $n \geq 2$, with real or complex coefficients if $t$ is any given positive number and

$$
Q_{t}=\left\{\operatorname{Max}_{0 \leq j \leq r}\left|\frac{a_{j}}{a_{n}}\right| t^{n-1}\right\}^{\frac{1}{n}}
$$

then all the zeros of $\mathrm{P}(\mathrm{z})$ lie in the disk

$$
|z| \leq \frac{1}{t}\left\{Q_{t}+Q_{t}^{2}+\ldots+Q_{t}^{r+1}\right\}
$$

where $0 \leq \mathrm{r} \leq \mathrm{n}-1$.

Taking $\mathrm{t}=1$, in equation (5), this reduces to Theorem $\mathrm{B}$.

We next present the following result which provides an interesting refinement of Theorem 1.

Theorem 2. Let

$$
P(z)=a_{n} z^{n}+a_{r} z^{r}+\ldots+a_{1} z+a_{0}
$$

$\mathrm{a}_{r} \neq 0 \quad 0 \leq \mathrm{r} \leq \mathrm{n}-1$ be a polynomial of degree $\mathrm{n} \geq 2$, with real or complex coefficients if $\mathrm{t}$ is any given positive number and

$$
Q_{t}=\left\{\operatorname{Max}_{0 \leq j \leq r}\left|\frac{a_{j}}{a_{n}}\right| t^{n-1}\right\}^{\frac{1}{n}},
$$


then all the zeros of $\mathrm{P}(\mathrm{z})$ lie in the disk

$$
|z| \leq \frac{1}{t}\left\{Q_{t}+\operatorname{Max}\left(Q_{t}^{2}, Q_{t}^{r+1}\right)\right\}
$$

where $1 \leq \mathrm{r} \leq \mathrm{n}-1$. The following result immediately follows from Theorem 2 by taking $\mathrm{t}=$ 1:

Corollary 1. Let $P(z)=a_{n} z^{n}+a_{r} z^{r}+\ldots+a_{1} z+a_{0}$

$a_{r} \neq 0 \quad 0 \leq r \leq n-1$ be a polynomial of degree $n \geq 2$, with real or complex coefficients if $t$ is any given positive number and

$$
Q_{t}=\left\{\operatorname{Max}_{0 \leq j \leq r}\left|\frac{a_{j}}{a_{n}}\right|\right\}^{\frac{1}{n}}
$$

then all the zeros of $\mathrm{P}(\mathrm{z})$ lie in the disk

$$
|z| \leq Q+\operatorname{Max}\left\{Q^{2}+\ldots+Q^{r+1}\right\}
$$

where $1 \leq \mathrm{r} \leq \mathrm{n}-1$,

\section{Proof of the Theorems}

Proof of Theorem 1. The companion matrix of the polynomial

$$
P(z)=a_{n} z^{n}+a_{r} z^{r}+\ldots+a_{1} z+a_{0}
$$

$\mathrm{a}_{r} \neq 0 \quad 0 \leq \mathrm{r} \leq \mathrm{n}-1$ of degree $\mathrm{n}$ is

$$
\mathrm{C}=\left(\begin{array}{cccccccc}
0 & 0 & \ldots & 0 & \ldots & 0 & & \frac{-a_{0} t^{n-1}}{a_{n} Q_{t}^{n-1}} \\
\frac{Q_{t}}{t} & 0 & \ldots & 0 & \ldots & 0 & & \frac{-a_{1} t^{n-2}}{a_{n} Q_{t}^{n-1}} \\
\ldots & \ldots & \ldots & \ldots & \ldots & \ldots \ldots & \\
0 & 0 & \ldots & \frac{Q_{t}}{t} & \ldots . . & 0 & \frac{-a_{r} t^{n-r-1}}{a_{n} Q_{t}^{n-r-1}} \\
\ldots & \ldots . & \ldots & \ldots & \ldots & \ldots & \ldots . \\
0 & 0 & \ldots . & 0 & \ldots . & \frac{Q_{t}}{t} & 0
\end{array}\right)
$$


By hypothesis ,

$$
Q_{t}=\left\{\operatorname{Max}_{0 \leq j \leq r}\left|\frac{a_{j}}{a_{n}}\right| t^{n-j}\right\}^{\frac{1}{n}}
$$

therefore,

$$
\left|\frac{a_{j}}{a_{n}}\right| t^{n-j} \leq Q_{t}^{n} \quad \text { for } j=0,1,2, \ldots, r \text {. and } Q_{t} \neq 0
$$

We take the matrix

$$
\mathrm{P}=\operatorname{diag}\left\{\left(\frac{Q_{t}}{t}\right)^{n-1},\left(\frac{Q_{t}}{t}\right)^{n-2}, \ldots,\left(\frac{Q_{t}}{t}\right), 1\right\}
$$

and form the matrix

$$
P^{-1} C P \quad\left(\begin{array}{cccccccc}
0 & 0 & \ldots & 0 & \ldots & 0 & & \frac{-a_{0} t^{n-1}}{a_{n} Q_{t}^{n-1}} \\
\frac{Q_{t}}{t} & 0 & \ldots & 0 & \ldots & 0 & & \frac{-a_{1} t^{n-2}}{a_{n} Q_{t}^{n-1}} \\
\ldots & \ldots & \ldots & \ldots & \ldots & \ldots \ldots & \\
0 & 0 & \ldots & \frac{Q_{t}}{t} & \ldots . . & 0 & \frac{-a_{r} t^{n-r-1}}{a_{n} Q_{t}^{n-r-1}} \\
\ldots & \ldots . & \ldots & \ldots & \ldots . & \ldots & \ldots . \\
0 & 0 & \ldots . & 0 & \ldots . & \frac{Q_{t}}{t} & 0
\end{array}\right) .
$$

Applying Gereshgorian Theorem to the columns of $\mathrm{P}^{-1} \mathrm{CP}$ and noting (7), it follows that all the eigen values of the matrix $\mathrm{P}^{-1} \mathrm{CP}$ lie in the circle

$$
\begin{aligned}
|z| & \leq \operatorname{Max}\left\{\frac{Q_{t}}{t}, \sum_{j=0}^{r}\left|\frac{a_{j}}{a_{n}}\right| \frac{t^{n-j-1}}{Q_{t}^{n-j-1}}\right\} \\
& \leq \frac{1}{t} \operatorname{Max}\left\{Q_{t}, \sum_{j=0}^{r} Q_{t}^{j+1}\right\} \\
& =\frac{1}{t}\left\{Q_{t}+Q_{t}^{2}+\ldots+Q_{t}^{r+1}\right\}
\end{aligned}
$$


Since the matrix $\mathrm{P}^{-1} \mathrm{CP}$ is similar to the matrix $\mathrm{C}$ and the eigen values of $\mathrm{C}$ are the zeros of the polynomial $\mathrm{P}(\mathrm{z})$, it follows that all the zeros of $\mathrm{P}(\mathrm{z})$ lie in the circle

$$
|z| \leq \frac{1}{t}\left\{Q_{t}+Q_{t}^{2}+\ldots+Q_{t}^{r+1}\right\}
$$

Which completes the proof of Theorem 1.

Proof of Theorem 2. The companion matrix of the polynomial

$$
P(z)=a_{n} z^{n}+a_{r} z^{r}+\ldots+a_{1} z+a_{0}
$$

$\mathrm{a}_{r} \neq 0 \quad 0 \leq \mathrm{r} \leq \mathrm{n}-1$ of degree $\mathrm{n}$ is given by

$$
\mathrm{C}=\left(\begin{array}{cccccccc}
0 & 0 & \ldots & 0 & \ldots & 0 & & \frac{-a_{0} t^{n-1}}{a_{n} Q_{t}^{n-1}} \\
\frac{Q_{t}}{t} & 0 & \ldots & 0 & \ldots & 0 & & \frac{-a_{1} t^{n-2}}{a_{n} Q_{t}^{n-1}} \\
\ldots & \ldots & \ldots & \ldots & \ldots & \ldots \ldots & \\
0 & 0 & \ldots & \frac{Q_{t}}{t} & \ldots . & 0 & \frac{-a_{r} t^{n-r-1}}{a_{n} Q_{t}^{n-r-1}} \\
\ldots & \ldots . & \ldots & \ldots & \ldots . & \ldots & \ldots . \\
0 & 0 & \ldots . & 0 & \ldots . & \frac{Q_{t}}{t} & 0
\end{array}\right)
$$

Proceeding similarly as in the proof of Theorem 1 and noting that

$$
\mathrm{P}=\operatorname{diag}\left\{\left(\frac{Q_{t}}{t}\right)^{n-1},\left(\frac{Q_{t}}{t}\right)^{n-2}, \ldots,\left(\frac{Q_{t}}{t}\right), 1\right\}
$$

with

$$
Q_{t}=\left\{\operatorname{Max}_{0 \leq j \leq r}\left|\frac{a_{j}}{a_{n}}\right| t^{n-j}\right\}^{\frac{1}{n}}
$$


It follows that the matrix

$$
P^{-1} C P \quad\left(\begin{array}{cccccccc}
0 & 0 & \ldots & 0 & \ldots & 0 & & \frac{-a_{0} t^{n-1}}{a_{n} Q_{t}^{n-1}} \\
\frac{Q_{t}}{t} & 0 & \ldots & 0 & \ldots & 0 & & \frac{-a_{1} t^{n-2}}{a_{n} Q_{t}^{n-1}} \\
\ldots & \ldots & \ldots & \ldots & \ldots & \ldots . & \\
0 & 0 & \ldots & \frac{Q_{t}}{t} & \ldots . & 0 & \frac{-a_{r} t^{n-r-1}}{a_{n} Q_{t}^{n-r-1}} \\
\ldots & \ldots & \ldots & \ldots & \ldots & \ldots & \ldots \\
0 & 0 & \ldots . & 0 & \ldots . & \frac{Q_{t}}{t} & 0
\end{array}\right) .
$$

Applying Gereshgorian Theorem to the columns of $\mathrm{P}^{-1} \mathrm{CP}$ and noting (7), it follows that all the eigen values of the matrix $\mathrm{P}^{-1} \mathrm{CP}$ therefore that of $\mathrm{C}$ lie in the circle

$$
\begin{aligned}
|z| & \leq \operatorname{Max}_{1 \leq j \leq r}\left\{\left|\frac{a_{0}}{a_{n}}\right| \frac{t^{n-1}}{Q_{t}^{n-1}}, \frac{Q_{t}}{t}+\left|\frac{a_{j}}{a_{n}}\right| \frac{t^{n-j-1}}{Q_{t}^{n-j-1}}\right\} \\
& \leq \frac{1}{t} \operatorname{Max}_{1 \leq j \leq r}\left\{Q_{t}, Q_{t}+Q_{t}^{j+1}\right\} \\
& =\frac{1}{t}\left\{Q_{t}+\operatorname{Max}\left(Q_{t}^{2}, Q_{t}^{r+1}\right\}\right.
\end{aligned}
$$

Since the matrix $\mathrm{P}^{-1} \mathrm{CP}$ is similar to the matrix $\mathrm{C}$ and the eigen values of $\mathrm{C}$ are the zeros of the polynomial $\mathrm{P}(\mathrm{z})$, therefore we conclude that all the zeros of $\mathrm{P}(\mathrm{z})$ lie in the circle denoted by (4). This proves Theorem 2 completely.

\section{References}

[1]. Alzer,H. On the zeros of a Polynomial,J.Approx.Theory,81(1995),421-424.

[2]. Aziz,A. Studies in zeros and Extremal properties of Polynomials, Ph.D. Thesis submitted to Kashmir University, 1981.

[3].Bell, H.E .Gereshgorian Theorem and the zero of polynomials, Amer. Math .Monthly, 72(1965),292-295.

[4].Cauchy,A.L. Exercises de mathe'matique in ceurres 9(1929),122.

[5].Guggenheimmer,H .On a note of Q.G.Mohammad, Amer.math.monthly,71(1964),5455.

[6].Lossers , O.P. Advanced problem 5739,Amer.Math.Monthly,78(1971),681-683. 
[7].Mohammad ,Q.G. On the zeros of polynomials,Amer.Math.Monthly,72(6),(1965), 631-633.

[8].Rahman,Q.I. A Bound for the moduli of the zeros of polynomials, Canad .math. Bull. 13(1970),541-542.

[9].Rahman,Q.I. and Schmeisser,G. Analytic Theory of Polynomials,Clarendon Press,Oxford, 2002.

[10].Walsh, J.L. An inequality for the roots of an algebraic equation. Ann.math. 25(1924), 283- 286. 